\title{
Performance Analysis of different Filters for Power Line Interface Reduction in ECG Signal
}

\author{
Yatindra Kumar \\ Assistant Professor \\ Department of EEE \\ G.B.Pant Engg College,Pauri
}

(U.K)India

\author{
Gorav Kumar Malik \\ Research Scholar \\ Department of EEE \\ G.B.Pant Engg College,Pauri
}

(U.K)India

\begin{abstract}
Over the years Computer aided analysis of ECG signal is gaining with tremendous amount of work being carried out all over the world. This paper is a small step on our part in that direction, ECG Electrocardiogram signal most comely known recognized and used biomedical signal, the ECG signal is very sensitive in nature, and even if small noise mixed with original signal the various characteristics of the signal changes, Data corrupted with noise must either filtered or discarded, filtering is important issue for design consideration of real time heart monitoring systems. The purpose of this paper is to quantify relative performance analysis of different filtering methods for power line interface reduction.

The data base for the performance analysis is created by simulation of ECG signal, an ideal ECG signal is best for performance analysis, then data base is corrupted with $50 \mathrm{~Hz}$ power line interface, the ability of different filter (use IIR Notch, Wiener, adaptive filter) are checked by changes in filtered signal, signal to noise ratio, Power of the signal, Power spectral density ,spectrogram of the signal, The location of peaks and its amplitude also measured by Pan Tompkins algorithm for performance analysis of filters. The results have clearly indicated that there is reduction in Power line noise in the ECG signal changes according to filter, and the best result is shown by adaptive filter we can see it easily in spectrogram, The results have been concluded using Mat lab and Simulated ECG database.
\end{abstract}

\section{General TERMS}

ECG, Filtering, Power line interface, Noise, IIR Notch, Wiener Filter, Adaptive Filter, Spectrogram , Power Spectral Density, Data base, R Wave, Amplitude, Preprocessing .

\section{KEYWORDS}

PSD, Power, Filtering, Periodogram ( (PSD Plot)

\section{INTRODUCTION TO ECG SIGNAL}

ECG is the graphical recording of the electrical activity of the heart, it is by far the most easily recognized biological signal, and it is also the one that is most commonly used for clinical diagnosis, and more important is the fact that the ECG wave shape is altered by cardiovascular diseases and abnormalities, each portion of the ECG waveform carries information that is relevant to the clinician in arriving at a proper diagnosis, The
Electrocardiograph signal taken from a patient was corrupted by an external noise, so that we need a proper way to get a noise free ECG signal a , simple ECG wave form shown in figure 1 , a ECG signal is a combination of $\mathrm{P}, \mathrm{T}, \mathrm{U}$ wave, and a QRS complex [6], The complete wave form is called an electrocardiogram with labels $\mathrm{P}, \mathrm{Q}, \mathrm{R}, \mathrm{S}$, and $\mathrm{T}$ indicating its distinctive features.

The $\mathrm{P}$ wave arises from the depolarization of the atrium. The QRS complex arises from depolarization of the ventricles. The T wave arises from re-polarization of the ventricle muscle.

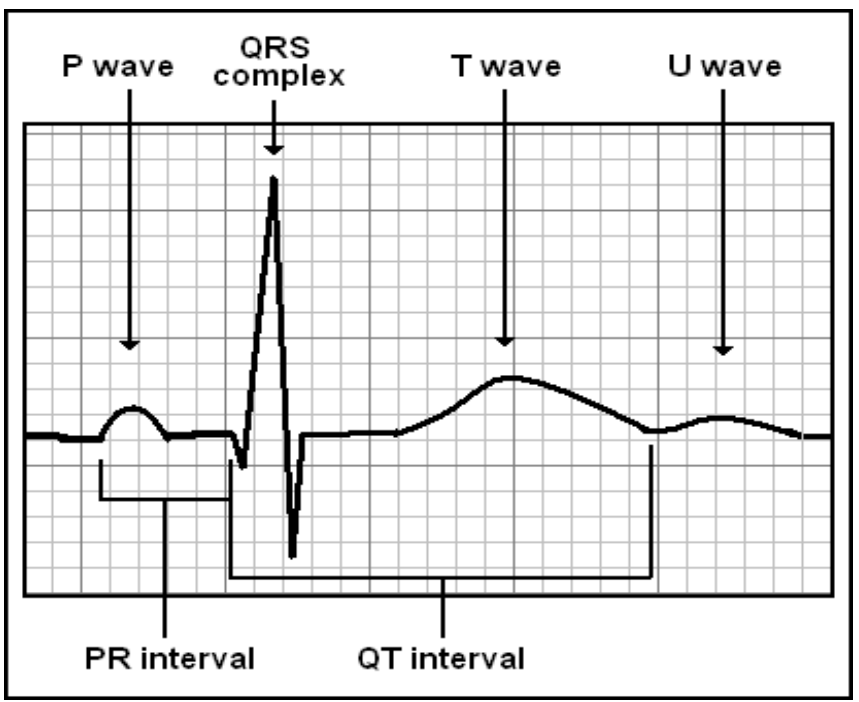

Figure 1 - ECG signal

\section{ECG SIGNAL PRE PROCESSING}

ECG preprocessing mean process the ECG signal before extract the information, Considerable attention has been paid to the design of filters for the purpose of removing power line interference [1], a most conmen interface in ECG signal, filtering problem being much more difficult to handle because of the substantial spectral overlap between the ECG and power line interface, the filtering techniques are primarily used for preprocessing of the signal and have as such been implemented in a wide variety of systems for ECG analysis . 


\section{TYPES OF ARTIFACT IN ECG SIGNAL}

The different kinds of interference waveforms (artifacts) added to the ECG signal during the recording, common Artifacts sources are

3.1 EMG related to coughing, breathing, or squirming affecting the ECG

3.1 Breath, lung, or bowel sounds contaminating the heart sounds (PCG).

3.3 Muscle sound (VMG) interference in joint sounds (VAG).

3.4 Maternal ECG getting added to the fetal ECG of interest.

3.5 Electrical interference external to the subject and recording system

3.6 High-frequency noise in the ECG

3.7 Motion artifact in the ECG

3.8 Noise due to variation of electrode skin contact impedance

3.9Power-line Interference in ECG signals

3.10 Noise generated by electronic devices used in signal processing circuits

There is various type of method to extract the ECG parameters from the Noisy ECG signal; very first need is analysis of ECG signal to get which type of noise mesh up with the signal, and of course power line interface reduction one of then.

The most commonly encountered periodic artifact in biomedical signals is the power line interference at $50 \mathrm{~Hz}$ or $60 \mathrm{~Hz}$. If the power-line waveform is not a pure sinusoid due to distortions or clipping, harmonics of the fundamental frequency could also appear. Harmonics will also appear if the interference is a periodic waveform that is not a sinusoid Power-line interference may be difficult to detect visually in signals having nonspecific waveforms such as the PCG or EMG, however, the interference is easily visible if present on well-defined signal waveforms such as the ECG pulse signals.

\section{SELECTING AN APPROPRIATE FILTER}

The ECG is a relatively strong signal with a readily identifiable waveform. Most types of interference that affect ECG signals may be removed by band pass filters; but Band pass filter is not able to give best result, our need changes according to, type of noises in ECG signal, in some signals the noise level very high and it is not possible to recognize it by single recording, it is important to gain a good understanding of the noise processes involved before one attempt to filter or preprocess a signal [1] [6].

The ECG signal taken for test is a simulated signal. All the following filters contain some noise one of them is white noise this noise is already included with the power line interference. We are focusing here for the removal of the power line interference noise at $50 \mathrm{~Hz}$ or $60 \mathrm{~Hz}$.
There are mainly five approaches to remove noise and interference, but in our algorithm for performance analysis we take only best three,

(1) Frequency-domain filtering (Notch Filter)

(2) Optimal (Wiener) filtering,

(3) Adaptive filtering

\subsection{NOTCH FI LTER}

It is well known or simplest filter to remove the power line interface notch filter compute the Fourier transform of the signal delete undesired component and the inverse Fourier transform [3]. There are two methods for implementation of the notch filter. First one is remove the artifact or set its value to zero. In second method the $50 \mathrm{~Hz}$ artifact set to be average value of the signal. Later methods not remove the $50 \mathrm{~Hz}$ component of the signal [4], but noise removing performance is average and in first one filter removes the $50 \mathrm{~Hz}$ component of the ECG signal.

\subsection{WIENER FILTER}

The notch filter and other pass band, band stop filters are fixed filter, they use only limited resources or we cannot change its performance according to our need [7].

Wiener filter use the statistical characteristics for noise removing process like reference signal or secondary recorded ECG signal. We can change its parameter to get the optimal results, so then we also called it optimal filter [11], Wiener filter theory provides for optimal filtering by taking into account the statistical characteristics of the signal and noise processes. The filter parameters are optimized with reference to a performance criterion, the output is guaranteed to be the best achievable result under the conditions imposed and the information provided.

\subsection{ADAPTIVE FILTERING}

Adaptive filters are self-designing filters based on an algorithm which allows the filter to "learn" the initial input statistics and to track them, if they are time varying. These filters estimate the deterministic signal and remove the noise uncorrelated with the deterministic signal [13], we have considered adaptive impulse correlated filter which requires the signal and a reference input [6]. The least mean square algorithm is used to adjust the weights of the adaptive filter in order to minimize the error and estimate the deterministic component through filter output [8].

\section{RESULTS}

The results are obtained by taking the Simulated ECG sample signals, the simulated ECG signal shown below. 


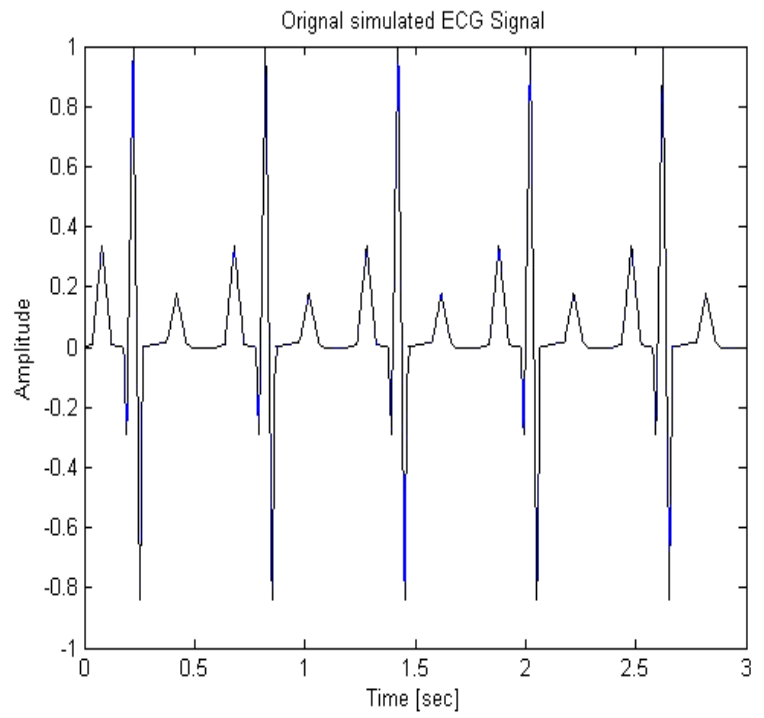

Figure 2 - Simulated ECG signal

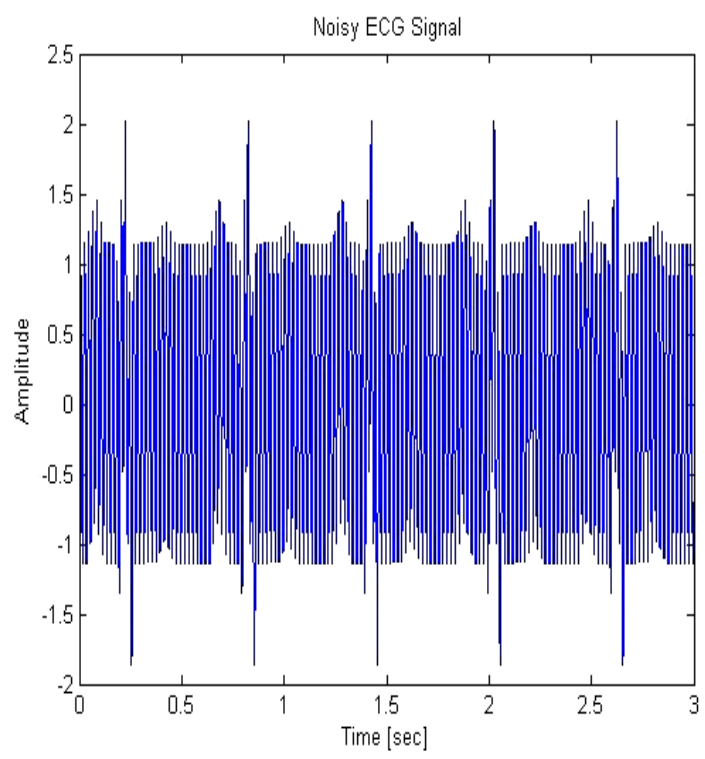

Figure 3 - Noisy ECG signal

The work is carried out in four steps: in the first step, we just simulate the ECG signal figure 1; the main advantage of simulated data is its idealness.

Then in step second we introduce the noise at $50 \mathrm{~Hz}$, noisy ECG signal and its periodogram (PSD Plot) shown below figure 2, 3 .

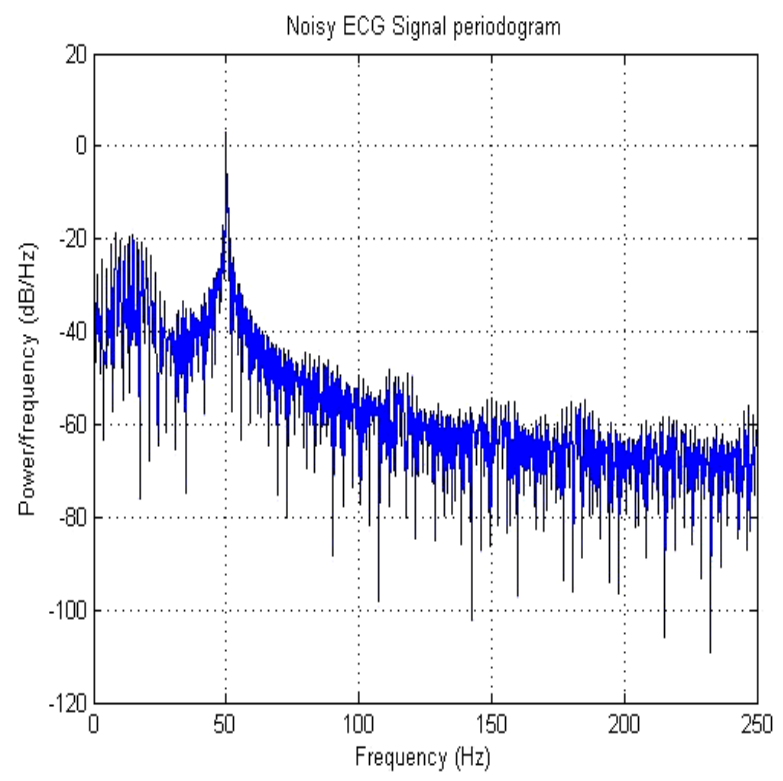

Figure 4 -Periodogram Noisy ECG signal

We can easily see a noise with high amplitude at $50 \mathrm{~Hz}$ in the periodogram figure- 4 , and then in step third we apply a high quality notch filter the notch filtered signal and its PSD shown below, the noise at $50 \mathrm{~Hz}$ completely removed ,but a small rise at first $\mathrm{R}$ Peak , and also some extra power at $50 \mathrm{~Hz}$ figure -5 , The signal to noise ratio and signal power also in table 1 , The location of R-peaks , and its amplitude also calculated by Pan Tompkins algorithm[9] shown in table 2.

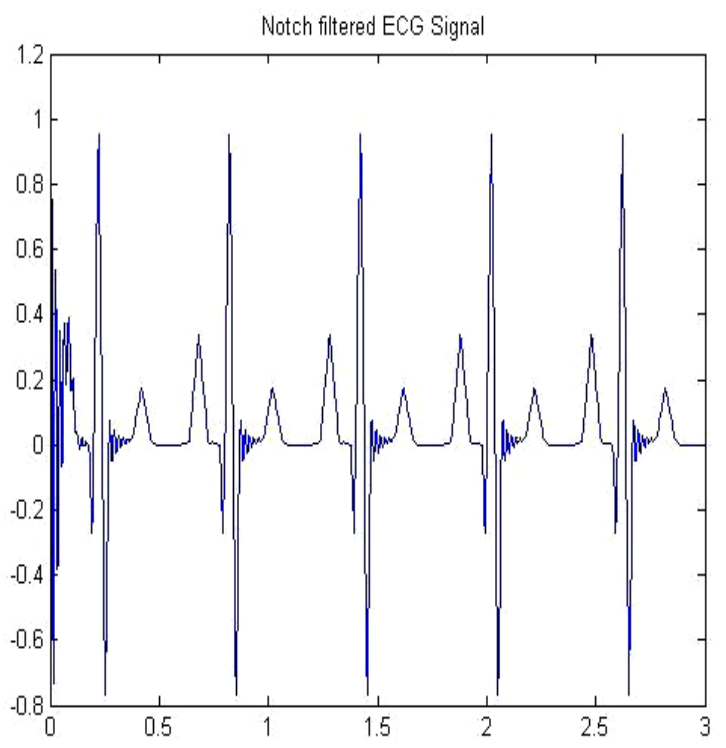

Figure 5 -Notch filtered ECG signal 


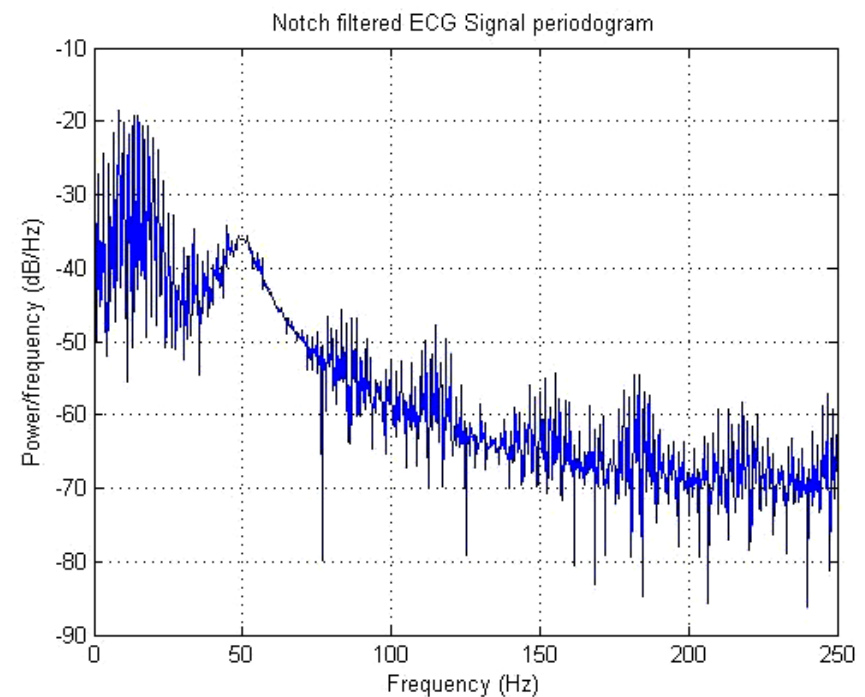

Figure 6 -Periodogram of Notch filtered ECG signal

The same Noisy ECG signal also filtered by wiener filter, where we take simulated noise as a reference noise signal, the output or filter signal and its periodogram shown below figure-7 and8, its clearly indicate that there is some reduction in ECG signal amplitude ,the performance table of SNR and Power of signal shown as Table 1 .

Table 1: Power of signal and its signal to noise ratio

\begin{tabular}{|l|c|c|}
\hline ECG Signal & Power (in dB) & SNR \\
\hline Simulated Signal & -16.83 & \\
\hline Noisy Signal & -4.14 & 0.27 \\
\hline Notch Filtered Signal & -16.49 & -12.48 \\
\hline Winer Filtered Signal & -22.97 & -18.87 \\
\hline $\begin{array}{l}\text { Adaptive Filtered } \\
\text { Signal }\end{array}$ & -15.49 & -11.66 \\
\hline
\end{tabular}

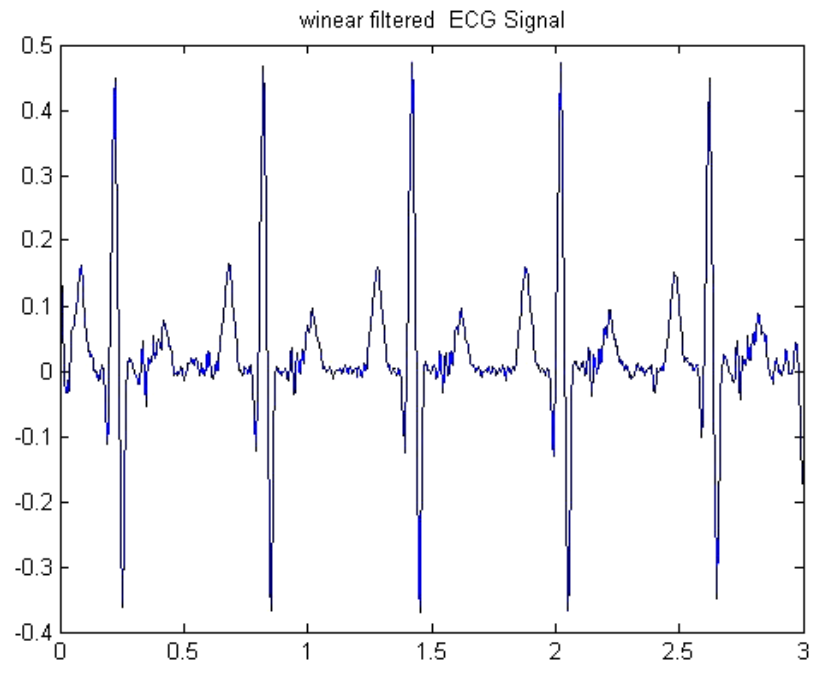

Figure 7 -Wiener filtered ECG signal

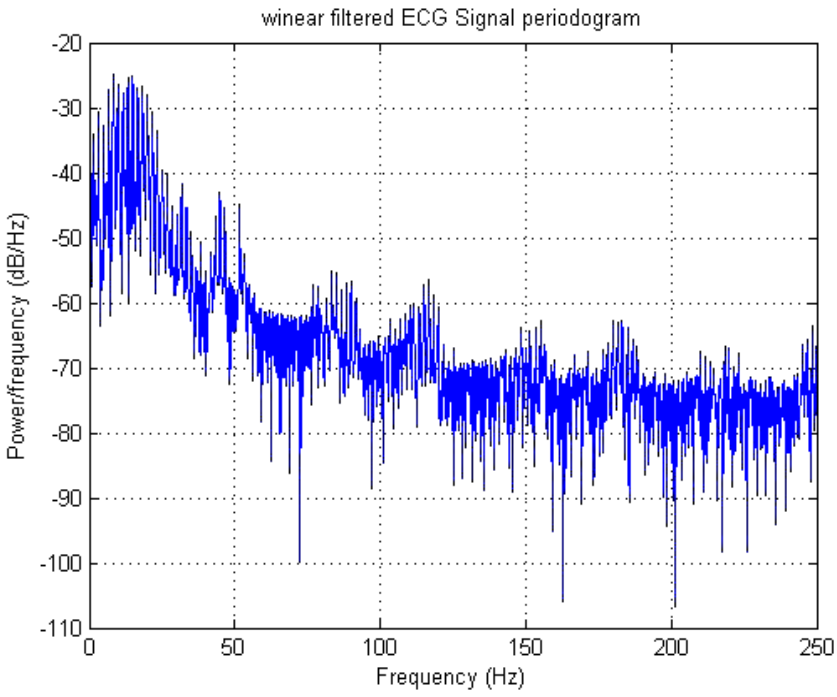

Figure 8 -Wiener filtered ECG signal periodogram

At last adaptive filter is use where we take simulated ECG signal as reference signal, and 100 iterations are use with tab value 5, the filtered signal is approximately same as the original signal, but there is some enhancement in the amplitude of filtered signal we can easily visualized it by figure of adaptive filter signal or with the help of spectrogram of three approaches, adaptive signal give the best result figure- 9 


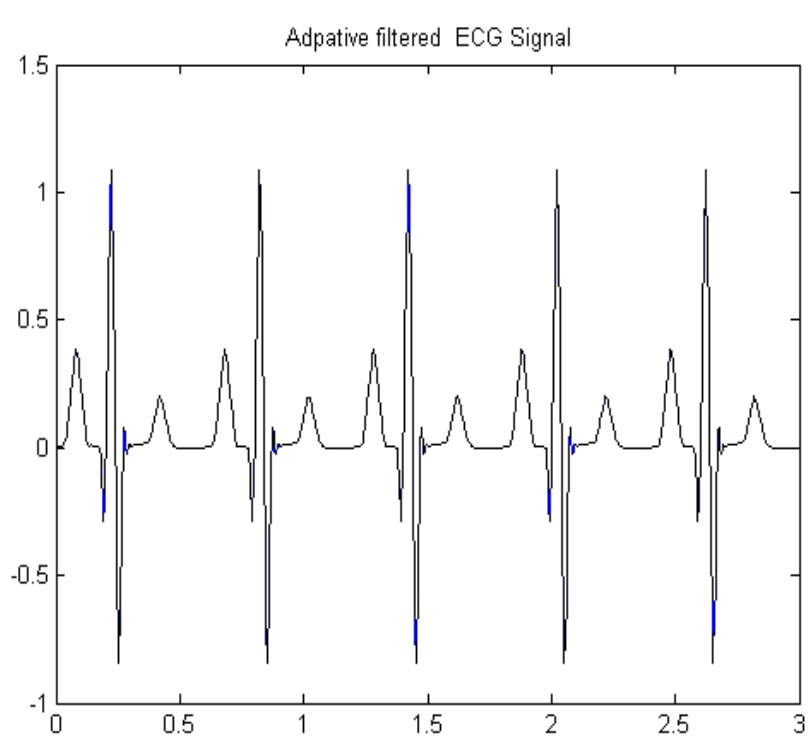

Figure 9 -Adaptive filtered ECG signal

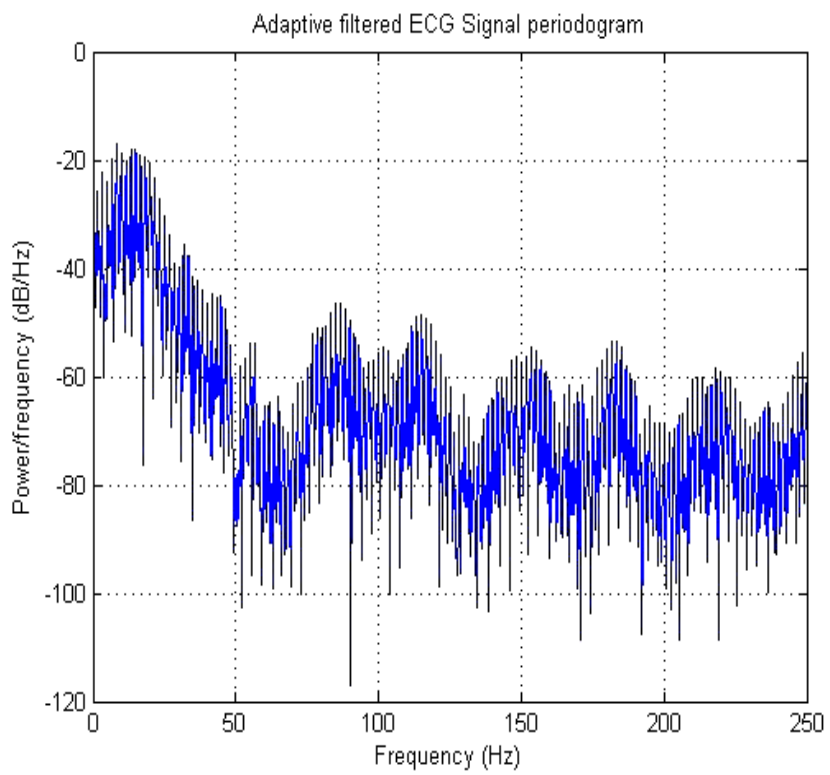

Figure 10 -Adaptive filtered ECG signal periodogram

The first and second spectrogram (figure 11, and 12) shows the simulated ECG, Noisy signal, notch filtered signal, wiener, and adaptive filtered spectrogram. Here we can easily see that the noise at $50 \mathrm{~Hz}$ and its reduction by filters, the top two performance are given by the notch and Adaptive filters but in notch filter we can easily see the some noise component at the starting of signal ,the first $\mathrm{R}$-peak is not actual peak as in table 2.
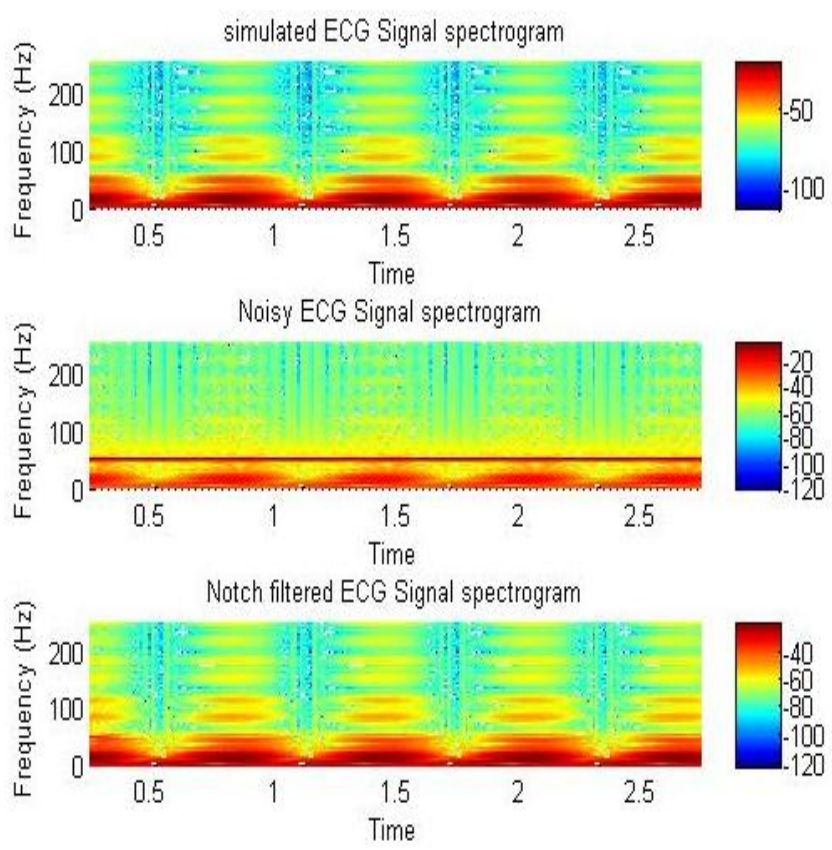

Figure 11 -Spectrogram of Simulated ECG, Noisy and Notch filtered signal
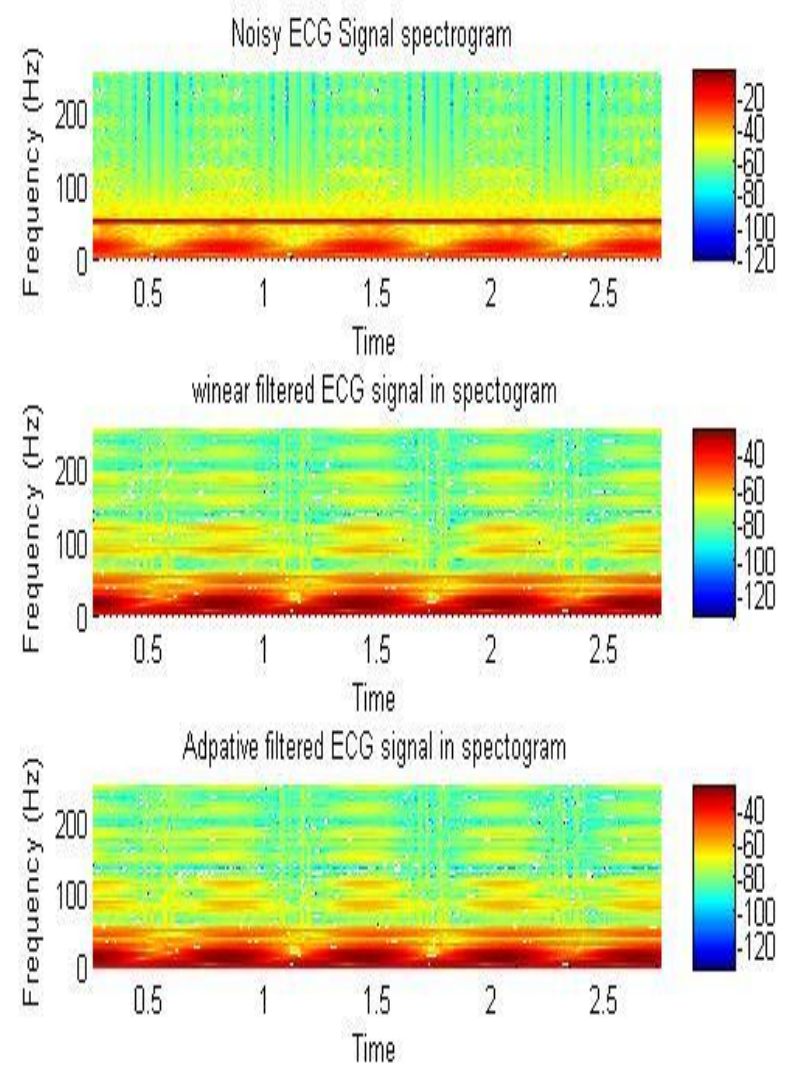

Figure 12 -Spectrogram of Noisy, wiener and Adaptive filtered signal 
Table 2: Peaks time, and amplitude of signal

\begin{tabular}{|c|c|c|c|c|c|}
\hline & $\begin{array}{l}\text { Simulate } \\
\text { d ECG } \\
\text { Signal }\end{array}$ & $\begin{array}{l}\text { Noisy } \\
\text { ECG } \\
\text { Signa } \\
\text { l }\end{array}$ & $\begin{array}{l}\text { Notch } \\
\text { Filtere } \\
\text { d } \\
\text { Signal }\end{array}$ & $\begin{array}{l}\text { Winer } \\
\text { Filtere } \\
\text { d } \\
\text { Signal }\end{array}$ & $\begin{array}{l}\text { Adaptiv } \\
\text { e } \\
\text { Filtered } \\
\text { Signal }\end{array}$ \\
\hline $\begin{array}{l}\text { I R Peak } \\
\text { Time (sec) }\end{array}$ & 0.112 & .014 & 0.003 & 0.112 & $\mathbf{0 . 1 1 2}$ \\
\hline $\begin{array}{l}\text { II R Peak } \\
\text { Time (sec) }\end{array}$ & 0.412 & .024 & 0.112 & 0.412 & $\mathbf{0 . 4 2}$ \\
\hline $\begin{array}{l}\text { III R } \\
\text { Peak } \\
\text { Time (sec) }\end{array}$ & 0.712 & .034 & 0.412 & 0.727 & $\mathbf{0 . 7 1 2}$ \\
\hline $\begin{array}{l}\text { IV R Peak } \\
\text { Time (sec) }\end{array}$ & 1.12 & .043 & 0.712 & 1.02 & $\mathbf{1 . 0 1 2}$ \\
\hline $\begin{array}{l}\text { I R Peak } \\
\text { Amplitud } \\
\text { e }\end{array}$ & 0.941 & 1.96 & 0.959 & 0.4229 & $\mathbf{1 . 0 2}$ \\
\hline $\begin{array}{l}\text { II R Peak } \\
\text { Amplitud } \\
\text { e }\end{array}$ & 0.941 & 1.96 & 0.925 & 0.4421 & $\mathbf{1 . 0 2}$ \\
\hline $\begin{array}{l}\text { III } \\
\text { Peak } \\
\text { Amplitud } \\
\text { e }\end{array}$ & 0.941 & 1.96 & 0.902 & 0.4479 & $\mathbf{1 . 0 2}$ \\
\hline $\begin{array}{l}\text { IV R Peak } \\
\text { Amplitud }\end{array}$ & $\mathbf{0 . 9 4 1}$ & $\mathbf{1 . 9 6}$ & $\mathbf{0 . 9 0 2}$ & $\mathbf{0 . 4 2 4 2}$ & $\mathbf{1 . 0 2}$ \\
\hline
\end{tabular}

\section{CONCLUSION:}

Adaptive filtering after tuning the taps to some optimum value gives the best results, however the IIR notch filter remove the artifact very simply or it is faster than other two algorithm, but it remove the $50 \mathrm{~Hz}$ component of the signal, and there also misinterpretation for first $\mathrm{R}$ Peak, so we cant take it because it change the heart rate. Wiener filters give the correct location or $\mathrm{R}$ Peak but amplitude of the signal distorted very much, and performance signal to noise ratio also not good effect, Adaptive filter give the best Signal to noise ratio and enhancement in the signal, we can easily visualize it in spectrogram. So that if we have a reference signal or noise model for an ECG signal then we can say adaptive filtering approach is best approach.

\section{REFERENCES}

[1] Rangaraj M. Rangayyan, 2005, Bio Medical signal analysis a case study approach, IEEE Press, JOHN WILEY \& SONS, INC

[2.] Tompkins WJ. Biomedical Digital Signal Processing. Prentice-Hall, Upper Saddle River, NJ, 1995.

[3] Peter handel, Analysis of notch filter with constrained pole zero IEEE Transactions on signal processing, vol. 421994.

[4]J. C. Huhta and J. G. Webster, 60-Hz interference in electrocardiography. IEEE Trans. Biomedical. Eng. 1973; 43:91-101.

[5] S.Pooranchandra, N.Kumaravel, 'A novel method for elimination of power line frequency in ECG signal using hyper shrinkage function', Digital Signal Processing.Volume18, Issue 2, March 2008, pp. 116-126.

[6] D.C Raddy, Biomedical signal processing Tata McGraw Hill2008.

[7] Haykin S. Adaptive Filter Theory Prentic hall, Upper Saddle River, NJ, 3rd edition, 1996.

[8] Widrow B, Glover Jr. JR, McCool JM, Kaunitz J, Williams CS, Hearn RH, Zeidler JR, Dong Jr. E, and Goodlin RC. Adaptive noise cancelling: Principles and applications. Proceedings of the IEEE, 63( 12): 1692-17 16, 1975

[9] Pan J and Tompkins WJ. A real-timse QRS detection algorithm. IEEE Transactions on Biomedical Engineering, 32-230-236, 1985

[10] Ju-Won-Lee, Gun-Ki Lee, 'Design of an Adaptive Filter with a Dynamic Structure for ECG signal Processing' International Journal of Control, Automation and Systems, vol.3, no.1, March 2005, pp. 137-42.

[11] M. Souden, J. Benesty, and S. Affes.On the Global Output SNR of the Parameterized Frequency-Domain Multichannel Noise Reduction Wiener Filter, IEEE SIGNAL PROCESSING LETTERS, VOL. 17, NO. 5, MAY 2010

[12] GD Clifford, A Shoeb, PE McSharry, BA Janz .Model based filtering, compression and classification of the ECG. IJBEM Vol. 7, No. 1, 2005 